\title{
DOCUMENTOS
}

\section{Universidades al servicio de la transformación social}

\section{Declaración institucional en el $25^{\circ}$ aniversario del martirio de los jesuitas de la UCA - I 7 de noviembre de 20 I 4}

Las Universidades y Centros de Educación Superior de la Compañía de Jesús de España (UNIJES) queremos conmemorar el $25^{\circ}$ aniversario del martirio de los jesuitas de la UCA (Universidad Centroamericana) de El Salvador como una interpelación a reflexionar sobre la función social de nuestros centros. El 16 de noviembre de 2014 se cumplen veinticinco años de aquella fatídica madrugada de 1989, en la que soldados del ejército salvadoreño irrumpieron en la residencia de nuestros compañeros jesuitas de la UCA, y mataron cruelmente a todos los que encontraron allí: Ignacio Ellacuría, Segundo Montes, Ignacio Martín-Baró, Amando López, Juan Ramón Moreno y Joaquín López y López. Tampoco queremos olvidar a las dos mujeres, madre e hija, que trabajaban en aquella casa, y que se refugiaron esa noche en ella, ante el toque de queda y la violencia de la guerra civil: Elba Ramos y Celina. Los soldados acabaron también con ellas porque no querían testigos, convirtiéndolas en símbolo del pueblo sufriente salvadoreño, de los más de 75.000 muertos que hubo en aquel país durante los diez años de guerra civil.

Estos seis jesuitas mártires, liderados por Ignacio Ellacuría, desde su profunda experiencia del Dios de Jesús y su compromiso con el pueblo, entendieron la universidad de un modo nuevo. La función de la universidad consiste en analizar la realidad histórica-que incluye todos los niveles de lo real-y en contribuir a su transformación, de tal manera que la realidad constituya cada vez más un espacio de libertad y justicia para todos los seres humanos. Como solía decir Ellacuría, esta aportación debe hacerse universitariamente, o sea, no cayendo en fáciles eslóganes, en planteamientos simplistas, o en derivas ideológicas; ni tampoco encerrándose en una torre de marfil supuestamente de alto nivel intelectual, sino poniendo el complejo aparato científico al servicio de verdaderos procesos de transformación histórica, una transformación que no podrá ser cosmética ni puntual, sino, por 
encima de todo, estructural, y que permita la construcción de sociedades más inclusivas y de mayor dignidad humana para todos.

El ejemplo de los mártires de la UCA nos interpela a nosotros, inmersos en un sistema universitario español y europeo sumamente complejo y competitivo, en el que son muchas las universidades que tratan de hacerse sitio. La abundancia de titulaciones, de facultades, de acreditaciones de la calidad-nacionales e internacionales-, la necesidad de obtener financiación para realizar la investigación científica y para ofrecer una docencia cuyo coste sea asumible por la sociedad; todo ello representa un exigente reto de mejora, $y$ hace que las diferentes comunidades universitarias estén trabajando cada día con intensidad y creatividad. Sin duda, nosotros, en UNIJES, nos sentimos orgullosos de la cantidad de jóvenes que cada año escogen estudiar en nuestros centros porque reconocen en ellos una indiscutible calidad en la formación académica y en la preparación para su futuro profesional. Nuestros graduados con éxito profesional son numerosos, y nos congratulamos porque hemos logrado prepararlos para ser excelentes profesionales en nuestro mundo actual, que es tan complejo.

Pero esto no nos basta. Queremos más.

Queremos que nuestros graduados sean capaces de analizar las raíces profundas de las injusticias estructurales que nos rodean, que tengan valor para comprometer su vida en la transformación de este mundo, que se sientan responsables del estado actual de la humanidad, que quieran ser agentes de cambio social, que contribuyan con su conocimiento a crear un sistema que sea respetuoso de la dignidad de la persona humana, de todas las personas, sin excepción, y respetuoso también de su hogar, que es la Tierra. Desde la perspectiva cristiana que nos anima institucionalmente, todo esto responde al designio de Dios, que quiere que todos sus hijos contribuyan a hacer realidad su reino de justicia y de paz.

Hoy, los profesores, investigadores, trabajadores de administración y servicios, estudiantes y jesuitas de UNIJES, precisamente porque constatamos que nuestros resultados están muchas veces lejos de estos ideales, queremos reconocernos deudores de Ignacio Ellacuría y de sus cinco compañeros, y solidarios con aquel pueblo salvadoreño maltratado por la injusticia y por la guerra. Y así como la UCA hizo un trabajo extraordinario en favor de la transformación de la sociedad salvadoreña, sin duda todavía inconcluso, nosotros queremos hoy poner nuestra docencia y nuestra investigación al servicio de la sociedad, y al servicio de una humanidad que sufre de modos distintos en todos los continentes.

Queremos hacerlo, y lo haremos, como decía Ellacuría, universitariamente. 